\title{
APRESENTAÇÃO
}

O Brasil vive, desde a Constituição de 1988, um período de mudanças na legislação e na política educacional que reconhecem a importância da primeira infância. As creches foram transferidas da área de Assistência Social para a da Educação, e foi antecipada a idade de ingresso das crianças no ensino fundamental ( 6 anos). A creche e a pré-escola passaram, pela primeira vez, a ter o seu financiamento previsto em lei, ao lado das demais etapas da educação básica, com a implantação do Fundo de Manutenção e Desenvolvimento da Educação Básica e Valorização dos Profissionais de Educação - Fundeb. Essas conquistas refletem em alguma medida a atuação de pesquisadores e militantes que, há décadas, defendem a construção de uma política de educação infantil com o compromisso de assegurar os direitos fundamentais da criança: seu bem-estar e desenvolvimento, alimentação sadia e higiene, direito à brincadeira, ao contato com a natureza e à ampliação de seus conhecimentos. Os progressos verificados na educação infantil são, no entanto, desiguais, se consideradas as diferentes realidades sociais, culturais e políticas no país. Esse fato tem suscitado uma questão na área dos estudos da infância, da educação e nas políticas públicas: que condições existentes na maioria das creches e pré-escolas permitem à criança exercer amplamente seu direito aos cuidados e à educação de qualidade?

O Tema em Destaque deste número reúne evidências de pesquisa em artigos nacionais e internacionais, que estimulam o debate sobre a qualidade da educação infantil no Brasil, oferecem algumas respostas possíveis e suscitam novas indagações. 
O primeiro artigo, espinha dorsal do dossiê, refere-se a resultados da pesquisa Educação infantil no Brasil: avaliação qualitativa e quantitativa, realizada por equipe de pesquisadores da Fundação Carlos Chagas e coordenada por Maria Malta Campos. As principais linhas do projeto da pesquisa foram definidas no edital que promoveu a concorrência internacional destinada a selecionar a instituição que desenvolveria o estudo. Essa proposta, uma iniciativa do Ministério da Educação que recebeu apoio do Banco Interamericano de Desenvolvimento, visava verificar a abrangência e a qualidade da oferta da educação infantil no país e avaliar em que medida variações na qualidade da educação pré-escolar oferecida às crianças têm impacto diferencial sobre seu desempenho nos anos iniciais do ensino fundamental.

O estudo adotou uma variedade de métodos para a obtenção de dados, incluindo análise documental, informações censitárias, entrevistas e observações dos ambientes de creches e pré-escolas, realizadas em 147 instituições de seis capitais brasileiras e a utilização de escalas empregadas internacionalmente como instrumentos de avaliação da qualidade de instituições de educação infantil. A opção por essas escalas justifica-se porque contemplam os principais critérios de qualidade adotados por documentos oficiais brasileiros, estão organizadas por duas faixas etárias correspondentes àquelas atendidas por creches e pré-escolas no país e abrangem grande variabilidade de situações. Além disso, pesquisas brasileiras, uma delas publicada nos Cadernos de Pesquisa ${ }^{1}$, já haviam feito uso desses instrumentos. Os resultados obtidos permitem refletir sobre os parâmetros de qualidade dos serviços oferecidos e ampliar o entendimento acerca de ambientes estimulantes para crianças pequenas. A aplicação das escalas de observação dos ambientes para crianças de creche e de pré-escola indicam níveis não satisfatórios de qualidade e reafirmam a necessidade de se promoverem mudanças nas práticas pedagógicas e se garantirem algumas condições básicas de funcionamento às instituições e aos profissionais que nelas atuam.

Com o objetivo de estabelecer um diálogo com estudos internacionais que utilizaram instrumentos semelhantes para apreciar a qualidade da educação infantil e observar similaridades ou dissimilaridades nos resultados, são incluídos outros três artigos. Seus autores - Sharon Lynn Kagan, dos Estados Unidos, Brenda Taggart et al., da Inglaterra, e Bob Myers, do México - participaram do Seminário internacional sobre avaliação da qualidade da educação infantil, realizado em São Paulo em 2010, em que os resultados parciais da pesquisa brasileira foram apresentados. No seminário, cada um dos pesquisadores pôde entabular uma troca de experiências e fazer comentários críticos.

O artigo de Sharon Lynn Kagan, ao relacionar conclusões de vários estudos semelhantes ao realizado no Brasil, chama a atenção para o baixo investimento nos serviços de qualidade e considera o fato como uma violação de direito fundamental das crianças. Observa que, em muitos países, a qualidade dos serviços de cuidado e educação oferecidos às creches como ambiente de desenvolvimento. Cadernos de Pesquisa, São Paulo, v. 36, n. 129, p. 573-596, set.dez. 2006. 
crianças pequenas é inadequada. Apresenta sete elementos que, no seu entender, compreenderiam a infraestrutura necessária para, juntamente com os programas, estabelecer um sistema de qualidade infantil: regulamentação, mecanismos de financiamento, estruturas governamentais que assegurem a equidade na oferta de serviços, capacidade de desenvolvimento e certificação profissional, parâmetros e mecanismos de avaliação contínua da formação, envolvimento de pais e da comunidade e, por fim, vinculação com escolas e serviços básicos de saúde. Para ela, a retirada de qualquer um desses elementos ou dos programas voltado a essa faixa etária implicará má-qualidade dos serviços de educação infantil.

Brenda Taggart e coautores descrevem as duas primeiras fases de um estudo longitudinal financiado pelo Departamento de Educação do Reino Unido, conhecido como projeto Effective provision of pre-school and primary education 1997-2008 - Eppe. Iniciado em 1997, encontra-se em sua quarta fase e envolve aproximadamente 3 mil crianças na Inglaterra a partir dos 3/5 anos. Inicialmente, seu objetivo foi investigar o impacto dos fatores relacionados à pré-escola, criança, família e aprendizagem em casa no desenvolvimento cognitivo e sociocomportamental até a idade de 7 anos. O sucesso da primeira fase do estudo levou à sua continuidade e ao acompanhamento das crianças até os 11 anos de idade, de modo a explorar também a influência de escolas primárias que elas frequentam. Na fase atual, a pesquisa acompanhará os adolescentes até os 16 anos (2013). O Eppe leva em consideração aspectos do ambiente familiar e reconhece seus efeitos na educação infantil, procurando mostrar que o sucesso das crianças é produto ao mesmo tempo do ambiente escolar e familiar. Por utilizar a escala Ecer-S (versão revisada), a mesma da pesquisa brasileira, abre possibilidades de comparação dos dados em alguns aspectos.

Não há entre nós tradição de pesquisas longitudinais na área da educação, assim, o artigo poderá inspirar pesquisadores a desenvolver projetos dessa natureza. Além disso, a equipe do Eppe elaborou uma extensão da escala com base nas orientações curriculares para crianças pequenas na Inglaterra e dirigida para a realidade da pré-escola. O instrumento inclui as práticas relacionadas à diversidade, assunto de interesse atual também nas pesquisas brasileiras. Estudos longitudinais, além de estabelecer os efeitos da educação infantil, favorecem a compreensão dos processos familiares (e outros, exteriores ao espaço escolar) e educacionais, subjacentes às mudanças nas trajetórias de desenvolvimento das crianças pequenas.

Robert Myers relata um projeto, ainda em curso no México, de elaboração e aplicação de instrumentos para avaliar a qualidade da educação pré-escolar. O recente processo de mudanças políticas nesse país gerou no setor educacional a necessidade de estabelecer indicadores de qualidade e equidade dos programas de educação para os primeiros anos, com ênfase na educação infantil. Um estudo específico realizado em 2001 resultou na elaboração de uma escala de avaliação da qualidade da educação em centros 
pré-escolares com 40 indicadores. O instrumento está em sua sexta versão. A aplicação da escala em dois estudos distintos, realizados entre 2002 e 2007 em diversos estados mexicanos, mostrou efeitos das mudanças políticas na qualidade da educação. A obrigatoriedade da educação infantil pode ter levado não necessariamente a mudanças positivas como, por exemplo, a redução da qualidade, na medida em que o aumento da oferta e da demanda provavelmente não correspondeu a uma melhora na infraestrutura e também devido ao próprio impacto das mudanças e da suas acomodações à nova realidade. Ou seja, os indicadores do processo educacional - medidos pelas escalas e outros instrumentos - são importantes não só por apontarem determinados resultados educacionais, mas também porque expressam um currículo oculto e a qualidade da vida experienciada em instituições educacionais que não contemplam necessariamente o modelo almejado por uma política universal. Contextos ecológicos e de vida diferenciados não permitem, na opinião de Myers, uma definição geral, única, de qualidade da educação. Ele defende flexibilidade nas definições de qualidade e nos instrumentos para medi-la, sendo recomendável permitir, e mesmo promover, acréscimos locais, levando em consideração o contexto.

Considerando a relativa dependência da qualidade da educação infantil em relação aos investimentos realizados pelo Estado, a pesquisa brasileira também realizou um estudo específico sobre o financiamento da educação infantil nas seis capitais da amostra. Marcos Edgar Bassi, convidado para realizar esse estudo, ouviu gestores e técnicos das Secretarias de Educação dos municípios investigados e analisou cuidadosamente relatórios e registros contábeis dos recursos aplicados ao desenvolvimento da educação infantil dos anos de 2007, 2008 e 2009. Com base na análise, calculou indicadores aproximados de gastos por aluno em creches e pré-escolas, públicas e conveniadas. Ao confrontar esses indicadores, apesar das muitas lacunas existentes, o autor constata que as desigualdades são ainda marcantes.

Os resultados da pesquisa Educação infantil no Brasil: avaliação qualitativa e quantitativa não são alentadores; eles reforçam a urgência na adoção de medidas de política educacional que permitam ganhos de qualidade na educação infantil, tanto na creche como na pré-escola. O exame das políticas municipais adotadas em quase todos os municípios do estudo mostrou que, nos últimos anos, as prefeituras estão pondo em prática diversas medidas para expandir a cobertura da educação infantil e melhorar a sua qualidade. Algumas políticas federais recentes, como a criação do Fundeb, o Proinfantil, a extensão dos programas federais de alimentação escolar e de distribuição de livros às instituições de educação infantil, parecem ter tido papel importante no estímulo e na efetivação dessas políticas, especialmente nos municípios das Regiões Nordeste e Norte. Os dados obtidos apontam aspectos específicos do funcionamento das creches e pré-escolas que necessitam pré-condições de infraestrutura mais adequadas, melhor orientação, formação continuada do pessoal - o que inclui gestores e equipes técnicas 
das secretarias - e sistemas de supervisão mais eficientes. As ações podem ter efeitos positivos não só na qualidade da educação infantil, mas também nas melhores oportunidades de aprendizagem propiciadas às crianças, na continuidade de sua escolarização.

É preciso, por tudo isso, considerar o contexto histórico recente, marcado por mudanças cujos impactos ainda estão em processo. Em novembro de 2009, com a promulgação da Emenda Constitucional n. 59, foi ampliada a obrigatoriedade da educação básica para os 4 aos 17 anos de idade. O prazo para sua progressiva implementação nas redes brasileiras é até 2016. Até lá, todos os sistemas de ensino têm de se adequar aos parâmetros a serem estipulados pelo Plano Nacional de Educação. Alguns pesquisadores e ativistas da educação, em particular da educação infantil, têm chamado a atenção para as consequências de uma possível cisão entre a creche e a pré-escola, em prejuízo do processo educacional de crianças de 0 a 3 anos. Além disso, a obrigatoriedade para os pais não garantirá a efetiva universalização do acesso das crianças pobres à pré-escola. Cumprir essa obrigação dependerá menos do interesse dos pais pela educação de seus filhos pequenos e muito mais da ampliação, pelo Estado, da oferta de creches e escolas com parâmetros de qualidade reiteradamente referenciados em estudos como os aqui apresentados.

Oportunamente complementa o dossiê um artigo de Peter Moss que discute a relação da pré-escola com a escolaridade primária. De modo instigante, o autor mapeia o terreno das escolhas disponíveis nas sociedades para pensar as possibilidades reais e potenciais da relação entre a educação infantil e o ensino obrigatório. A preocupação de Moss está no processo de transição vivenciado pela criança de uma instituição para outra. Para ele, as experiências institucionais das crianças podem variar bastante e afetar a relação entre a educação infantil e a escola obrigatória, bem como a transição de uma etapa para a outra. A experiência de passar por uma pré-escola integrada ao sistema escolar (no caso, ao ensino fundamental) seria diferente de outra em que a educação infantil é desvinculada do ensino fundamental, como as creches, jardins de infância, pré-escolas isoladas que não são necessariamente "escolares", frequentadas desde os primeiros anos de vida.

Moss reporta-se particularmente aos países-membros da Organização para Cooperação e Desenvolvimento Econômico - OCDE - nessa discussão. As questões postas pelo autor são igualmente relevantes para países como o Brasil, visto que nossas políticas educacionais têm promovido a expansão do atendimento infantil e refletem, em alguma medida, tendências globais de ampliação da obrigatoriedade escolar. As orientações brasileiras são coerentes com o que estabelece a Convenção sobre os direitos da criança, da ONU, que reconhece o direito à educação, mediante oferta do ensino primário obrigatório e gratuito para todos (Artigo 28), como também entende que o direito à educação nos primeiros anos de vida se inicia com o nascimento e está intimamente ligado ao direito das crianças pequenas ao máximo desenvolvimento (Artigo 6.2). 
A seleção de artigos de Tema em Destaque buscou apontar aos leitores questões cruciais, tanto para os profissionais diretamente encarregados da educação infantil quanto para os formuladores das políticas da área, bem como estimular a reflexão sobre as possibilidades de soluções que considerem o direito das crianças pequenas à educação como um processo de aprendizagem e de crescimento amplo, no qual o cuidado está incluído como uma dimensão ética integrada à experiência educativa.

\section{SANDRA UNBEHAUM}

sandrau@fcc.org.br 